\title{
On Integrated Peer-Assisted Learning Clusters Among Students in a Nigerian University
}

\author{
Oluwafolakemi Ala, Harbin Engineering University, China \\ iD https://orcid.org/0000-0002-2196-7259 \\ Hongtao Yang, HuaQiao University, China
}

\begin{abstract}
Peer interaction to assist and learn from each other has been extended online in recent times. This study was conducted to find the pattern of participation in integrated peer-assisted learning and to investigate factors known to affect such participation among students in their peer-assisted learning clusters. The pattern of participation was established through the frequency with which the respondent used their preferred mode of peer interaction. Structural equation modeling was implemented to study the relationship between participation and the factors considered. Social media is the most prevalent among the online means of interaction considered. Conflict, cohesion, and effective leadership in the clusters have more direct effects on the other factors considered. The frequency of participation does not correlate significantly with the other personal and interpersonal factors considered. These findings suggest that the decisions for voluntary participation in peer-assisted learning clusters are possibly driven by other factors such as academic need.
\end{abstract}

\section{KEYWORDS}

E-Learning, Learning Technology, Mobile Learning, Online Learning, Peer-Assisted Learning, Peer-to-Peer Interaction, Shared Database, Social Media, University Students, Virtual Learning Communities

\section{INTRODUCTION}

Learning, preparation for gainful employment, career advancement, and development into responsible citizens are some of the overarching goals of university education for students. Peer-assisted learning has emerged as an essential pedagogy in university education as students seek to meet the demand of their studies. This has evolved from the unofficial interaction between students to a tool recognized, encouraged, and implemented by many universities based on its merits (Huijser, Kimmins, \& Evans, 2008; Schuetz et al., 2017). Learning is known to be maximized when the process focuses directly on what the learner wants to learn as opposed to what the teacher wants to teach. Therefore, studentcentered learning allows individual students to take responsibility for the accumulation of personal skills and knowledge. This form of collaborative learning is beneficial to all participants in terms of cognitive gains and positive learning outcomes (Osman, Sauid, \& Azizan, 2015). The student-centered learning that is characteristic of peer-assisted learning complement the formal mode of learning.

Peer-assisted learning refers to situations where students support each other academically through teaching and learning from each other. Peer-assisted learning has been explained from the five meta-

\section{DOI: 10.4018/IJICTE.287103}

This article published as an Open Access article distributed under the terms of the Creative Commons Attribution License (http://creativecommons.org/licenses/by/4.0/) which permits unrestricted use, distribution, and production in any medium, provided the author of the original work and original publication source are properly credited. 
spaces in the concept of 'spaces of influence' covering aspects of cognitive and social congruence. The core elements of PAL include collaboration, reflection, communication, self-and peer assessment (Boud, Cohen, \& Sampson, 2016). The implementation of such initiatives is sometimes labeled Peer-Assisted Student Support (PASS) or Supplemental Instruction (SI) among others (Packham \& Miller, 2000). These schemes address three elements of student need: engaging learning experience, practical and timely support services, and a sense of community.

Peer-assisted learning can happen in a variety of ways. It can also cut across formal, informal learning clusters. The development of domain-specific peer-assisted learning digital models has interested learning scientists and teacher education researchers for a while (Latifi, Noroozi, Hatami, \& Biemans, 2019; Noroozi \& Mulder, 2017; Noroozi, Weinberger, Biemans, Mulder, \& Chizari, 2013). Such efforts have covered aspects of understanding the cognitive models that are involved in giving and receiving peer feedback (Nicol, Thomson, \& Breslin, 2014), types of feedbacks (Bayerlein, 2014; Latifi et al., 2019), the role of gender (Noroozi et al., 2020), change in attitude (Huisman, Saab, van Driel, \& van den Broek, 2018), and the contribution such feedbacks make on the students' essay writing skills and learning in general(Noroozi, Biemans, \& Mulder, 2016; Noroozi, Kirschner, Biemans, \& Mulder, 2018). In many of these studies, peer feedbacks were received/given via a digital platform.

There are also instances where a face-to-face peer-assisted learning scheme has been offered to students as a free and voluntary learning support option under peer-tutoring experiments. In such programmes, a pool of tutors (students) is recruited based on the recommendation of faculty staff, paid, trained, and provided with instructional materials. With these supports, participation, effectiveness, quality, and cost of the programme can be monitored. The role of the tutor and tutee can be either fixed or flipped depending on the variance of the programme being implemented (Miravet, Ciges, \& García, 2014). Notwithstanding, the programme remains flexible, collaborative, interactive, intentional, systemic, and mutually beneficial. These programmes were a low-cost initiative to increase student participation in peer-assisted learning in general(Kim, Jillapali, \& Boyd, 2021), and reduced the failure rate (Pugatch \& Wilson, 2018). However, even the meager cost for such a programme could be a limitation to its implementation where there are budget constraints.

Part of the factor that makes peer-assisted learning so effective is the ease of communication between peers. Potential intimidatory factors such as highly structured lectures, tutorials, and hierarchical differences are minimized. The advantages of these schemes to students have been identified as additional assistance with challenges; especially from peers, a broader perspective on problems, access to expertise, more meaningful participation, and a stronger sense of identity. Peerassisted learning can be particularly beneficial to students from diverse cultural and educational backgrounds especially first-year students and international students(Huijser et al., 2008) as they adapt to a new environment. It has also been leveraged to sustain learning during the COVID-19 pandemic(Ala, Yang, \& Ala, 2021a; Oyediran, Omoare, Owoyemi, Adejobi, \& Fasasi, 2020; Oyedotun, 2020).

Study shows that students in strictly online study groups desire more face-to-face interaction to have a 'sense of community (Drouin \& Vartanian, 2010). This underscores the fact that any form of learning technology is not a replacement for face-to-face interaction, however, it can help where such is not feasible or provide a platform for extended engagement beyond the confines of face-toface interaction. New technology tools can complement traditional forms of learning (Moghavvemi, Sulaiman, \& Jaafar, 2018) by removing traditional barriers. The new trend of increasing access to communication technology devices and broadband is also driving a new form of integrated peerassisted learning in recent times. Technology has been employed as a tool to assist in the objectives of peer-assisted learning.

The online component in integrated peer-assisted learning complements face-to-face interaction. However, some responses can be delayed and students could face some difficulties in communicating abstract and technical ideas due to the limitations of the means of interaction. Advances in social media platforms have also made them more adaptable for online peer-assisted learning. Features 
such as chat logs, file sharing, video calls, group calls, voice messages, emojis have in recent times enriched online communication(Mustafa \& Al-Jabri, 2016). Laptops, smartphones, and other devices with internet connections are ubiquitous and versatile in helping students stay connected with peers online and for academic purposes(Al-hariri \& Al-hattami, 2017).

Peer-assisted learning initiatives have been judged useful but the personal and inter-personal factors that determine its effectiveness have not been fully explored. There have been studies on student collaboration in physical groups, cohorts, or online independently. However, studies that analyze integrated peer-assisted learning groups (groups with face-to-face and online interactions) are rare to date. Finally, this study is limited to the Federal University of Technology, Akure (FUTA) students within a structured peer-assisted learning cluster. Issues of possible internet addiction are beyond the scope of this study.

\section{Peer-Assisted Learning Cluster}

Peer-assisted learning clusters are established to assist students. Peer-assisted learning interactions are not restricted to face-to-face interaction (Miravet et al., 2014; Pugatch \& Wilson, 2018) as such interactions can also happen through a communication medium (Moldovan, 2014) or both alternatively. The students considered in this study belong to at least a project group, assignment group, or research group. Participation is usually voluntary. Membership of a cluster requires students to be available, participate, and interact with each other (Jung, Young, \& Kim, 2017).

Participation was measured by the frequency of face-to-face interactions with learning peers or use the electronic or online means of interaction. Advantages of participating in the clusters such as getting feedback from colleagues, social support, supervisory coaching, and mentorship make it an avenue for personal growth, learning, and development such that it is a 'resource' for the students(Salanova, Schaufeli, \& Martínez, 2010).

It is common practice for the students to form clusters where they can work with and learn from peers where such support is not offered formally. There are nuances in the composition of the groups depending on the objective. Although, lecturers sometimes divide their students into small groups to work on a joint task. It is also common practice that attendance at a 'tutorial' will be higher than normal as examination approaches or when part of the agenda is to solve some 'assignment' questions that the students are required to submit for assessment. There is no evidence that these clusters are part of a strategic approach to learning by the Federal University of Technology, Akure (FUTA), rather they are commissioned at the instances of the lecturers or by the students to meet an academic need(Ala et al., 2021a).

\section{Quality}

The agenda of cluster sessions are often flexible and determined by the identified need. This ensures that the focus is on useful and relevant materials to the participants. However, the quality of the responses that peers provide online is also important. Quality can be measured in terms of relevance, ease of understanding, accuracy, completeness, reliability, and timeliness of the knowledge shared within the cluster. A question measures each of these yardsticks and the response is given on a fivelevel Likert scale with five corresponding to strongly agree and one to strongly disagree. Although tutors usually make reference to the same materials in circulation among their classmates, the quality of the learning in the clusters can be improved when the programme is supported and monitored (Miravet et al., 2014).

\section{Conflict}

Some clusters are established for students to collaborate and work as a team. Different opinions are expressed when members process ideas, approaches, or information about the task. The fact that there are divergent views indicates a commendable level of interest, engagement, and robust discussion among group members. How argument facilitates learning is better appreciated through collaborative 
argumentation-based learning (CABLE) research(Baker, Andriessen, \& Schwarz, 2019). Gender has also been found to play a role in argumentative peer feedback (Noroozi et al., 2020). The extent of such engagement can be measured through how the students perceive the opinions of group members about the project, goals, objectives, and deliverables.

\section{Cohesion}

Earlier findings in a United Kingdom university show that female students tend to attend PASS in groups while most of their male counterparts come either in their company or alone. Cordial relationships among group members affect their ability to work together especially on joint tasks. Cohesion measures the nature and quality of the human bonds among group members. Other researchers have found a link between group cohesiveness, effective communication, and group performance. Cohesiveness grows with the meaningful participation of group members. Collective energy is considered a catalyst for cohesion in a team (Cole, Bruch, \& Vogel, 2012; Müceldili \& Oya, 2015). However, some researchers have muted the idea that an extreme level of group cohesion can be counter-productive.

\section{Leadership}

Group leaders are essential in directing the affairs of the group. The establishment of an online cluster requires that the leader receives basic training on moderating the online discussion. The leadership effectiveness of the group can be measured from the interpersonal skills of the leader. An effective leader communicates and encourages open communication, is open to new ideas, responds to the members' needs, and encourages respect and recognition of the members' input. Leadership also has a role to play in ensuring fairness and resolving conflict among the members.

\section{Peer Influence}

Group members can encourage each other's participation. Evidence of this has been provided in the pattern of female students' attendance. Peer influence is defined as the degree to which the participation of group members affects each other when executing a task. Students use continuous feedback from peers to adjust their work. The input of peers encourages members to continue participating in the group. Interactions increase the sense of community felt by students, and in turn, this sense of community encourages more interaction (Cooke, 2016).

\section{Trust}

The level of trust among members affects team performance. Trust is the degree to which a member believes other members have each other's interest in the group's assignment (Anderson and Narus, 1990). An increased level of trust leads to a higher level of openness and communication (Fernie, Green, Weller, \& Newcombe, 2003). Trust within a team is accumulated as members interact, collaborate, and exchange ideas with other members of the group. Trust is needed to build a cohesive group and play an important role in the communication and performance of virtual teams (Sarker, Ahuja, Sarker, \& Kirkeby, 2011). Trust in a virtual team is catalyzed by the reputation of the members. Students in this study have both online and face-to-face interactions with their group members, thus have more opportunities to build trust. These dynamics are expected to improve their online participation since they are not likely to remain anonymous online(Budu, 2018).

\section{Expectation}

The expectation of a reward is one of the motivations for sharing knowledge with others. Personal motivation for knowledge sharing varies widely (Matzler \& Mueller, 2011; Yu, Lu, \& Liu, 2010). Since individuals and their willingness to share is at the core of participation in the clusters, getting a grasp of those expectations is essential to the group. Motivations underlying individuals' behaviors 
have been explained by the Expectancy Value Theory(Borders, Earleywine, \& Stanley, 2004). The Social Exchange theory also suggests that individuals exchange valuable resources in the expectation of a benefit. The expected reward can be tangible or intangible.

\section{Materials and Methods}

This is non-experimental research because the student participation was only observed without any deliberate manipulation of the variables. It is also cross-sectional because the data were gathered at a single instance.

\section{Participants}

Data for this study was collected among the students of the Federal University of Technology, Akure, Nigeria. 1997 students were sampled from seven Schools consisting of 50 academic departments with a total enrollment of 18,672 students. The Schools include the School of Agriculture and Agricultural Technology (SAAT), School of Engineering and Engineering Technology (SEET), School of Earth and Mineral Sciences (SEMS), School of Environmental Technology (SET), School of Management Technology (SMAT), School of Sciences (SOS), School of Health and Health Technology (SHHT), and School of Computing (SOC). The SPSS Random Number Generator was used to select 50\% of the departments and a total enrollment of 9779 . Then, the study adopts $20 \%$ of the sampling frame as its sampling size, this amounts to 1941. This implies that from each School, $20 \%$ of the sampling frame was selected to form the sample size. The Level (Table 1) of the study is an indication of how long a student has been enrolled in the University.

Table 1. The level of the respondents

\begin{tabular}{|l|l|l|}
\hline Level & \multicolumn{1}{|c|}{$\mathbf{n}$} & \multicolumn{1}{c|}{$\%$} \\
\hline 1.00 & 350 & 17.9 \\
\hline 2.00 & 337 & 17.2 \\
\hline 3.00 & 355 & 18.1 \\
\hline 4.00 & 309 & 15.8 \\
\hline 5.00 & 350 & 17.9 \\
\hline 6.00 & 255 & 13.0 \\
\hline
\end{tabular}

All the participants in this study use a smartphone and can access the internet through a variety of means (some at a personal cost). The means of electronic peer-peer interactions considered in this study were selected based on the recommendations of computer-supported collaborative learning research. They include both synchronous and asynchronous tools that are accessible with just a smartphone. Synchronous has been reported to promote personal engagement while asynchronous promote cognitive engagement as students have more time to reflect on the content (He \& Huang, 2017).

\section{Procedure}

Approval for this study was granted by the appropriate authorities before the data were collected. Participants were briefed on the objective of the survey. Assurances were provided by not gathering identifying data and that the data will be reported only in an aggregate fashion. Data gathering was from April to November of 2019. The data collected were checked for completeness and errors 
before acceptance for entry into an Excel sheet that was imported to IBM SPSS 23. 38 responses were rejected on this basis.

\section{Measure and Analysis}

The study is designed to measure the pattern of peer-assisted learning among students and the contribution of some factors. The questionnaires measure how frequently a student participates in any form of cluster learning activity face-to-face or otherwise. The highest frequency score goes to respondents that participate daily. Most cluster sessions are scheduled weekly but some students could be part of two or more clusters running concurrently or with schedule overlap. The frequency and quality of group communication are related to enhanced group decision-making and cohesiveness (Karanxha \& Greenlee, 2010). The undergraduate groups usually consist of peers at the same level while the graduate groups have members at different levels in their graduate study with shared research interests.

Each of the factors in Sections 1.1-1.8 were measured by standardized questionnaires. They were tested for test-retest reliability in a pilot study conducted in Federal Polytechnic Ado-Ekiti. 300 students volunteered to participate in the preliminary study. The pilot study confirms the internal consistency and reliability of the instruments with the lowest Cronbach alpha of 0.92 in the factor. Table 2 is a list of the questionnaires.

\section{Table 2. Standard questionnaires used}

\begin{tabular}{|l|l|l|}
\hline & \multicolumn{1}{|c|}{ Source } & \multicolumn{1}{c|}{ Cronbach- $\boldsymbol{\alpha}$} \\
\hline Quality & DeLone \& McLean, 2003 & 0.930 \\
\hline Conflict & Jehn et al., 1999 & 0.925 \\
\hline Cohesion & Chang \& Bordia, 2001 & 0.925 \\
\hline Leadership & Glenn \& Parker, 1998 & 0.927 \\
\hline Trust & Jarvanpaa \& Leidner, 2006 & 0.929 \\
\hline
\end{tabular}

\section{Result}

Preliminary findings from this research establish that peer-assisted learning is happening among the students even when their colleges have not formally launched the scheme. All the respondents indicated that they participate in an integrated peer-assisted learning group even though participation in most of them is not compulsory. Online interactions are also reported to be added advantage to the clusters as some of the respondents remarked that 'it is an easy and convenient way of getting immediate help anytime'.

\section{Descriptive Statistics}

There are more males (66.6\%) than females (33.4\%) among the respondents. The highest proportion (70.9\%) were between the ages of 21 and 25. Other demographic characteristics of the sampled population are presented in Table 3.

\section{Pattern of participation}

Breakdown of the means of interaction and how often students engage in their clusters show that $60.3 \%$ of the respondents use social media daily for participation (Table 4). The contribution of social media to learning has been reported in a recent study (Moghavvemi et al., 2018). 38\% attend cluster 
Table 3. Demographic variables of the respondents

\begin{tabular}{|c|c|c|c|}
\hline Variable & & Frequency & Percentage \% \\
\hline \multirow{4}{*}{ Age } & $15-20$ & 409 & 20.9 \\
\hline & $21-25$ & 1386 & 70.9 \\
\hline & $26-30$ & 134 & 6.9 \\
\hline & $36-40$ & 27 & 1.4 \\
\hline \multirow{2}{*}{ Sex } & Male & 1302 & 66.6 \\
\hline & Female & 654 & 33.4 \\
\hline \multirow{2}{*}{ Degree } & Bachelors & 1701 & 87.0 \\
\hline & Masters & 255 & 13.0 \\
\hline \multirow{2}{*}{ Marital Status } & Single & 1940 & 99.2 \\
\hline & Married & 16 & 0.8 \\
\hline
\end{tabular}

Table 4. Participation (\%) in peer-assisted learning clusters among FUTA students

\begin{tabular}{|l|l|l|l|l|l|}
\hline & \multicolumn{1}{|c|}{ Daily (1) } & $\begin{array}{c}\text { A few times } \\
\text { a week (2) }\end{array}$ & $\begin{array}{c}\text { Once a week } \\
\text { (3) }\end{array}$ & \multicolumn{1}{|c|}{$\begin{array}{c}\text { Once a } \\
\text { month (4) }\end{array}$} & $\begin{array}{c}\text { Never/Not } \\
\text { applicable (5) }\end{array}$ \\
\hline Face-to-face & 25.0 & 38.0 & 19.9 & 14.5 & 2.6 \\
\hline Phone call & 44.6 & 26.6 & 13.9 & 9.3 & 7.6 \\
\hline Email & 16.5 & 21.2 & 16.0 & 17.5 & 28.8 \\
\hline Social media * & 60.3 & 19.3 & 9.4 & 4.6 & 6.5 \\
\hline Shared Databases & 24.3 & 20.1 & 16.9 & 14.9 & 23.8 \\
\hline
\end{tabular}

sessions 'a few times a week' while another $19.9 \%$ attended at least 'once a week.' $44.6 \%$ make phone calls daily, while $71.2 \%$ made such calls more than once a week. Approximately a quarter of the respondents access a shared database daily. Email is the least used among the respondents with $28.8 \%$ of respondents saying they had "never used it.

There are established patterns of participation in the groups on a daily, weekly, and monthly basis. Social media, Phone calls, and face-to-face interactions are the most frequently used means of peer interaction and learning (Figure 1).

\section{Average participation}

The mean scores of the leading factors affecting participation in knowledge sharing among the participants are expectation(3.77) and quality(3.57). The standard deviations of the variables score show that responses are most divergent in how frequent (1.41) they participated in the clusters and on the influence of their peers (1.11) on their participation but most convergent on the tutees' assessment of the quality of learning in the clusters $(0.87)$. 


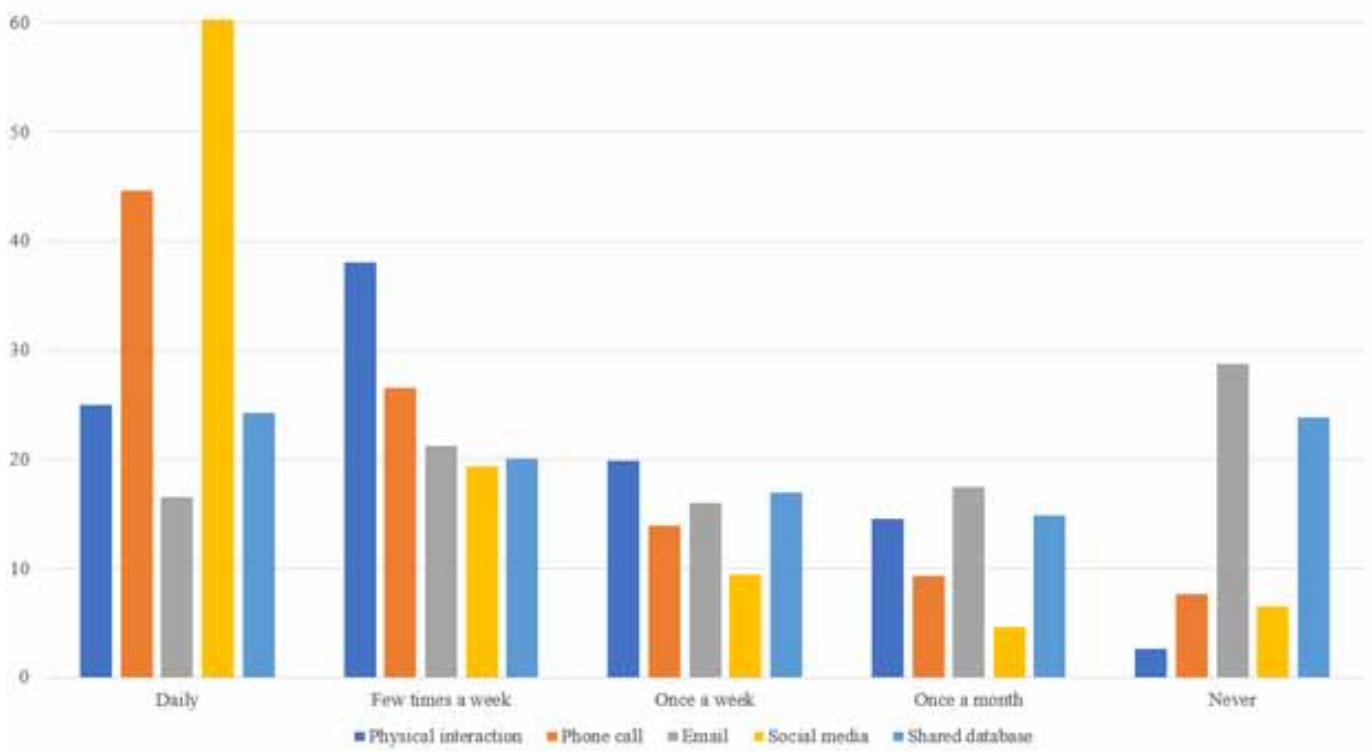

\section{Correlations}

The Pearson coefficients in Table 5 show the relationship between frequency and the factors examined.

The strongest positive correlations can be seen between leadership-cohesion $(.685 \mathrm{p}<0.01)$, leadership-conflict $(-.613 \mathrm{p}<0.01)$, and expectation-quality $(.580 \mathrm{p}<0.01)$. The relationship between the frequency of participation and the other variables is the weakest. There are significant positive correlations between the frequency of participation and the other variables with the exceptions of

Table 5. Correlations of factors affecting participation in peer-learning clusters

\begin{tabular}{|l|l|l|l|l|l|l|l|l|l|l|}
\hline & mean & s.d & \multicolumn{1}{|c|}{$\mathbf{1}$} & $\mathbf{2}$ & $\mathbf{3}$ & $\mathbf{4}$ & $\mathbf{5}$ & $\mathbf{6}$ & $\mathbf{7}$ & $\mathbf{8}$ \\
\hline $\begin{array}{l}\text { 1.Frequency of } \\
\text { interaction }\end{array}$ & 3.54 & 1.41 & 1 & & & & & & & \\
\hline 2. Quality & 3.57 & 0.87 & -.044 & 1 & & & & & & \\
\hline 3. Expectation & 3.77 & 0.98 & .001 & $.580^{* *}$ & 1 & & & & & \\
\hline 4. Trust & 3.38 & 1.00 & -.007 & $.477^{* *}$ & $.424^{* *}$ & 1 & & & & \\
\hline 5 Peer Influence & 3.54 & 1.11 & .023 & $.345^{* *}$ & $.460^{* *}$ & $.553^{* *}$ & 1 & & & \\
\hline 6. Conflict & 3.51 & 1.01 & $.060^{* *}$ & $.353^{* *}$ & $.498^{* *}$ & $.432^{* *}$ & $.559^{* *}$ & 1 & & \\
\hline 7. Cohesion & 3.50 & 0.99 & .018 & $.423^{* *}$ & $.461^{* *}$ & $.576^{* *}$ & $.535^{* *}$ & $.536^{* *}$ & 1 & \\
\hline 8. Leadership & 3.12 & 0.92 & $.059^{* *}$ & $.407^{* *}$ & $.539^{* *}$ & $.496^{* *}$ & $.550^{* *}$ & $.613^{* *}$ & $.685^{* *}$ & 1 \\
\hline
\end{tabular}

${ }^{*}$ Correlation is significant at the 0.05 level (2-tailed).

${ }^{* *}$. Correlation is significant at the 0.01 level (2-tailed). 
trust $(-.007 \mathrm{p}<0.001)$ and quality $(-.044 \mathrm{p}<0.001)$. A two-way relationship is expected among the variables as they moderate each other.

\section{Direct and Indirect Effects}

The structural equation model (SEM) was used to detect the direct and indirect effect that the factors have upon each other in AMOS 20 (Arbuckle, 2011). We assumed initially a nested model in which all the variables interact based on our knowledge of behavioral complexities. Model adequacy was determined by $\chi^{2}$ tests $(\mathrm{P}>0.05)$, goodness-of-fit index (GFI, $\left.>0.9\right)$, Akaike Information Criteria (AIC), and root square mean errors of approximation (RSMEA, < 0.05), Hooper et al., 2008).

Conflict among members have direct effect on their expectation $(.296 \mathrm{p}<0.001)$, cohesion $(.673$ $\mathrm{p}<0.001)$, leadership $(.254 \mathrm{p}<0.001)$ and trust $(.566 \mathrm{p}<0.001)$ among them. Cohesion has a direct effect on leadership $(.508 \mathrm{p}<0.001)$ and peer-influence $(.845 \mathrm{p}<0.001)$ among members. The leadership of the group has a direct effect on peer influence $(.228 \mathrm{p}<0.001)$. The quality of the knowledge shared among members directly impacts the cohesion $(.401 \mathrm{p}<0.001)$ among them. The level of trust affects the expectation $(.368 \mathrm{p}<0.001)$ and cohesion $(.496 \mathrm{p}<0.001)$ among members.

Peer influence has a negative effect on the quality $(-.278 \mathrm{p}<0.001)$ and cohesion $(-.882 \mathrm{p}<0.001)$ among members. The frequency of participation has a negative effect on the quality $(-.029 \mathrm{p}<0.138)$ and peer-influence $(-.018 \mathrm{p}<0.464)$ though both are insignificant.

Peer-influence-cohesion, trust-quality, and cohesion-quality have direct effects on each other. The relationship between Peer-influence and Cohesion is strong $(.845 \mathrm{p}<0.001,-.882 \mathrm{p}<0.001)$ and at the same level of significance in both directions. The variables form a complex web of indirect effects. The direct effects are either complimented or undermined by these indirect effects. The effects of other variables on the frequency of participation are not significant. Solid lines in Figure 2 indicate positive path coefficients and dashed lines indicate negative path coefficients. The red lines indicate effects that are not significant. Width of arrows indicates strength of the standardized path coefficient (*** $\mathrm{P}<0.001 ; * * \mathrm{P}<0.01$; $* \mathrm{P}<0.05)$.

Figure 2: Direct and indirect effects of the factors on each other

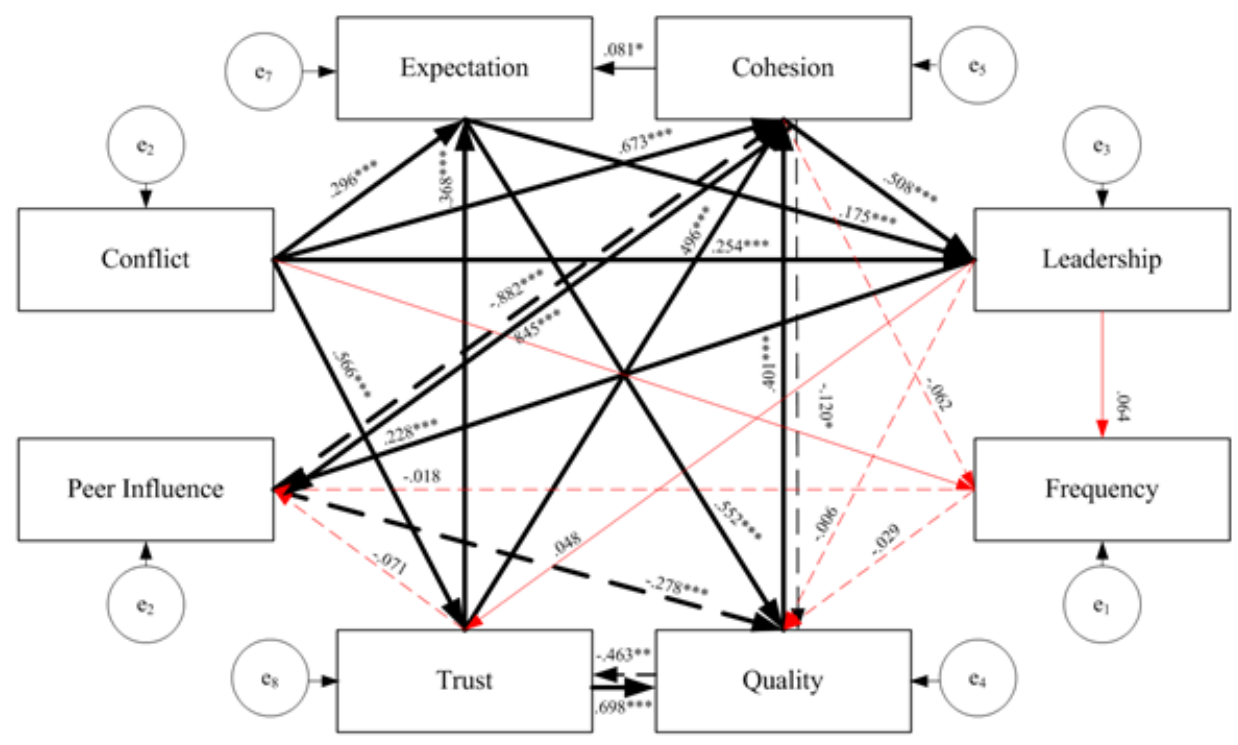




\section{DISCUSSION}

\section{The pattern of participation in integrated peer-assisted learning}

Integrating online communities with learning systems is a growing trend in education that enables students to interact with peers (Lai et al., 2019). FUTA students are leveraging on the various means of interaction available to them to learn, collaborate, and solve their academic problems (Ala et al., 2021a). These clusters seem to emerge to meet the academic needs of the students. Past researchers concluded that urgent academic and social needs are some of the reasons students make use of these groups. There are also findings that attendance is usually highest among younger students. More than $70 \%$ of the respondents in this study are $£ 25$ years old. Also, simplicity, cost-effectiveness, immediacy, and community are some of the motivations for the increased use of social media platforms among college students (Baytiyeh, 2018). This finding agrees with the theoretical standpoint that technology acceptance can be expected based on its perceived usefulness and perceived ease of use(Davis, 1989).

The finding that emails and shared databases the least patronized daily but are still used on a weekly and monthly basis at a higher percentage compared to the rest agrees with similar research(Ala, Yang, \& Ala, 2021b). The trend noticed with emails and shared databases is likely as a result of either convenience or the adaptability of these platforms to the nature of information and interactions peers are seeking from each other. There is no guaranty of instant reply to emails. Notwithstanding, electronic repositories such as shared databases have been reported to encourage knowledge reuse and strengthen knowledge sharing (Kankanhalli, Lee, \& Lim, 2011).

\section{Correlations between factors affecting participation in peer-assisted learning cluster}

The relationship between the frequency of face-to-face interaction and the other variables is the weakest. Urgent academic and social needs have been identified as some of the major reasons students participate in cluster activities (Packham \& Miller, 2000). The academic and social need likely features when students are in the processes of deciding to either participate or otherwise, while other factors investigated in this study become more compelling once a student has made the initial decision to be part of the group. Also, face-to-face interaction may be least desired since there are other means of interaction to use.

The correlation between conflict and cohesion is equally strong, positive, and significant (.536 $\mathrm{p}<0.01)$ with formal having a direct effect on the latter $\left(.673^{* * *}\right)$. The expectations of members are tied to the quality of knowledge shared within the cluster. The dimension of the social, psychological, and personal rewards that come from sharing what a student knows with his peers is dependent on the relevance, timeliness, and usefulness of the knowledge shared. These findings are in agreement with results on collaborative argumentation-based learning research (Baker et al., 2019) and the study on assessment of the timeliness of peer feedback (Bayerlein, 2014).

\section{Direct and Indirect Relationships Between Factors Affecting Participation in Peer-Assisted Learning Cluster}

Graphical illustration of the direct and indirect effects of the variables on each other shows a nested relationship between the variables. However, the conflict has a direct effect on the highest number of other variables. The level of engagement as a result of the diversity of opinions and approaches among members directly affects their expectations, group cohesion, level of trust, frequency of participation, and the leadership of the cluster. This is expected since achieving the core goal of the cluster is dependent on how effectively the members can interact with each other. Peer influence and cohesion have a cyclic effect on each other that is at the same level of significance $(\mathrm{p}<0.001)$. Evidence of such a relationship in peer-assisted learning research has been reported. There is evidence that how male and female students socialize reflects on the pattern of their attendance in 
peer-assisted learning groups (Packham \& Miller, 2000) and the quality of feedback they provide for their peers(Noroozi et al., 2020).

\section{CONCLUSION}

An integrated version of peer-assisted learning is going on among the students of the Federal University of Technology, Akure. There is evidence that the students connect with their peers faceto-face and online to learn from each other. Social media platforms can be accessed easily from a variety of devices such as smartphones, laptops, tablets, and even desktop computers once there is a connection to the internet. Besides, most social media platforms have features for synchronous and asynchronous means of communication and temporary storage for the chat log. Since social media platforms are usually designed for social interactions online, more research is required on how these platforms can be better suited for the academic needs of their student users.

The relationship between the factors affecting integrated peer-assisted learning schemes is nested. Conflict, which is a measure of the robustness of engagement going on among group members has a direct effect on most of the other variables. The availability of multiple means of interaction for peers could be the reason why the level of engagement has a direct impact on other factors. Other findings show that students consider the reward(s) of participation, quality of the knowledge shared and are influenced by their peers. Institutions in Nigeria considering launching peer-assisted learning schemes can consider a system that recognizes the students' participation in the clusters, standardization of the materials shared and encouraging the groups to emerge from existing social structures as some of the strategic guidelines. Also, the scheme will be beneficial to the students if it can be offered as a standardized learning support programme. Finally, integrated peer-assisted learning schemes have the potential to support formal online learning that has become common in recent times.

\section{Limitations And Direction for Future Research}

Although the specific conclusions of this study may have been affected by the geographical location of this research, it can at the least be a guide for similar studies in other regions. The data analyzed in this study were self-reported and susceptible to social desirability biases. It is also possible that learning interactions among colleagues that do not belong to the same clusters are included by the respondents. The role of specific cluster characteristics such as type, size, duration, social and cognitive congruity between tutor and tutees, etc. in meeting its objective should be further researched in detail. The university libraries can also consider ways of embedding their support services in these learning clusters.

\section{AUTHORS CONTRIBUTION}

Ala O: Conceptualization, Methodology, Writing-Original Draft, Writing- Review \& Editing, Visualization, Formal Analysis, Project Administration.

Yang H.: Ethical approval, Supervision 


\section{REFERENCES}

Al-hariri, M. T., \& Al-hattami, A. A. (2017). Impact of students' use of technology on their learning achievements in physiology courses at the University of Dammam. Journal of Taibah University Medical Sciences, 12(1), 82-85. doi:10.1016/j.jtumed.2016.07.004 PMID:31435218

Ala, O. G., Yang, H., \& Ala, A. A. (2021a). Leveraging integrated peer-assisted learning clusters as a support for online learning. Interactive Learning Environments, 1-13. doi:10.1080/10494820.2021.1943454

Ala, O. G., Yang, H., \& Ala, B. K. (2021b). Characteristics and comparison of peer-assisted learning interactions among university students in Harbin, China. Social Sciences \& Humanities Open, 4(1), 100164. doi:10.1016/j. ssaho.2021.100164

Baker, M. J., Andriessen, J., \& Schwarz, B. B. (2019). Collaborative Argumentation - Based Learning. In International Handbook on Dialogic Education. Routledge. doi:10.4324/9780429441677-8

Bayerlein, L. (2014). Students' feedback preferences: How do students react to timely and automatically generated assessment feedback? Assessment \& Evaluation in Higher Education, 39(8), 916-931. doi:10.1080/0260293 8.2013.870531

Baytiyeh, H. (2018). Students' use of mobile technologies: Motivational factors. International Journal of Information and Communication Technology Education, 14(1), 73-85. doi:10.4018/IJICTE.2018010106

Borders, A., Earleywine, M., \& Stanley, J. (2004). Predicting Problem Behaviors with Multiple Expectancies: Expanding Expectancy-Value Theory. Adolescence, 39(155), 539-550. PMID:15673229

Budu, J. (2018). What makes learners share feedback or not in an online community for education. International Journal of Information and Communication Technology Education, 14(2), 48-59. doi:10.4018/IJICTE.2018040104

Cole, M. S., Bruch, H., \& Vogel, B. (2012). Energy at work: A measurement validation and linkage to unit effectiveness. $<$ ALIGNMENT.qj $></$ ALIGNMENT $>10.1002 /$ job

Cooke, N. A. (2016). Information Sharing, Community Development, and Deindividuation in the eLearning Domain. Online Learning, 20(2), 244-260. doi:10.24059/olj.v20i2.614

Davis, F. D. (1989). Perceived Usefulness, Perceived Ease of Use, and User Acceptance of Information Technology. Management Information Systems, 13(3), 319-340. doi:10.2307/249008

Drouin, M., \& Vartanian, L. R. (2010). Students' Feelings of and Desire for Sense of Community in Face-toFace and Online Courses. Quarterly Review of Distance Education, 11(3), 147-159.

Fernie, S., Green, S. D., Weller, S. J., \& Newcombe, R. (2003). Knowledge sharing: Context, confusion and controversy. International Journal of Project Management, 21(3), 177-187. doi:10.1016/S0263-7863(02)00092-3

He, J., \& Huang, X. (2017). Collaborative Online Teamwork: Exploring Students' Satisfaction and Attitudes with Google Hangouts as a Supplementary Communication Tool. Journal of Research on Technology in Education, $O(0), 1-12$. doi:10.1080/15391523.2017.1327334

Huijser, H., Kimmins, L., \& Evans, P. (2008). Peer Assisted Learning in Fleximode: Developing an Online Learning Community. Australasian Journal of Peer Learning, 1, 51-60.

Huisman, B., Saab, N., van Driel, J., \& van den Broek, P. (2018). Peer feedback on academic writing: Undergraduate students' peer feedback role, peer feedback perceptions and essay performance. Assessment \& Evaluation in Higher Education, 43(6), 955-968. doi:10.1080/02602938.2018.1424318

Jung, Y., Young, J., \& Kim, H. (2017). A psychological empowerment approach to online knowledge sharing. Computers in Human Behavior, 74, 175-187. doi:10.1016/j.chb.2017.04.039

Kankanhalli, A., Lee, O. D., \& Lim, K. H. (2011). Knowledge reuse through electronic repositories: A study in the context of customer service support. Information \& Management, 48(2-3), 106-113. doi:10.1016/j. im.2011.02.002

Karanxha, Z., \& Greenlee, B. J. (2010). A Study of Group Dynamics in Educational Leadership Cohort and Non-Cohort Groups. Journal of Research on Leadership Education, 5(11). 
Kim, S. C., Jillapali, R., \& Boyd, S. (2021). Impacts of peer tutoring on academic performance of first-year baccalaureate nursing students: A quasi-experimental study. Nurse Education Today, 96(November), 104658. 10.1016/j.nedt.2020.104658

Latifi, S., Noroozi, O., Hatami, J., \& Biemans, H. J. A. (2019). How does online peer feedback improve argumentative essay writing and learning? Innovations in Education and Teaching International, 0(0), 1-12. doi:10.1080/14703297.2019.1687005

Matzler, K., \& Mueller, J. (2011). Antecedents of knowledge sharing - Examining the influence of learning and performance orientation. Journal of Economic Psychology, 32(3), 317-329. doi:10.1016/j.joep.2010.12.006

Miravet, L. M., Ciges, A. S., \& García, O. M. (2014). An Experience of Reciprocal Peer Tutoring at the University. Procedia: Social and Behavioral Sciences, 116, 2809-2812. doi:10.1016/j.sbspro.2014.01.661

Moghavvemi, S., Sulaiman, A., \& Jaafar, N. I. (2018). Social media as a complementary learning tool for teaching and learning: The case of youtube. The International Journal of Management Education, 16(August), 37-42. 10.1016/j.ijme.2017.12.001

Moldovan, L. (2014). Innovative method of peer assisted learning by technology and assessment of practical skills. Procedia Technology, 12, 667-674. doi:10.1016/j.protcy.2013.12.547

Müceldili, B., \& Oya, E. (2015). Cultivating group cohesiveness: The role of collective energy. Procedia: Social and Behavioral Sciences, 207, 512-518. doi:10.1016/j.sbspro.2015.10.121

Mustafa, I., \& Al-Jabri, I. M. (2016). Social networking, knowledge sharing, and student learning: The case of university students. Computers \& Education, 99, 14-27. doi:10.1016/j.compedu.2016.04.007

Nicol, D., Thomson, A., \& Breslin, C. (2014). Rethinking feedback practices in higher education: A peer review perspective. Assessment \& Evaluation in Higher Education, 39(1), 102-122. doi:10.1080/02602938.2013.795518

Noroozi, O., Biemans, H., \& Mulder, M. (2016). Relations between scripted online peer feedback processes and quality of written argumentative essay. Internet and Higher Education, 31, 20-31. doi:10.1016/j. iheduc.2016.05.002

Noroozi, O., Hatami, J., Bayat, A., van Ginkel, S., Biemans, H. J. A., \& Mulder, M. (2020). Students' online argumentative peer feedback, essay writing, and content learning: Does gender matter? Interactive Learning Environments, 28(6), 698-712. doi:10.1080/10494820.2018.1543200

Noroozi, O., Kirschner, P. A., Biemans, H. J. A., \& Mulder, M. (2018). Promoting Argumentation Competence: Extending from First- to Second-Order Scaffolding Through Adaptive Fading. Educational Psychology Review, 30(1), 153-176. doi:10.1007/s10648-017-9400-z

Noroozi, O., \& Mulder, M. (2017). Design and evaluation of a digital module with guided peer feedback for student learning biotechnology and molecular life sciences, attitudinal change, and satisfaction. Biochemistry and Molecular Biology Education, 45(1), 31-39. doi:10.1002/bmb.20981 PMID:27322926

Noroozi, O., Weinberger, A., Biemans, H. J. A., Mulder, M., \& Chizari, M. (2013). Facilitating argumentative knowledge construction through a transactive discussion script in CSCL. Computers \& Education, 61(1), 59-76. doi:10.1016/j.compedu.2012.08.013

Osman, S., Sauid, M. K., \& Azizan, N. (2015). Knowledge Sharing Patterns among Undergraduate Students in Universiti Teknologi MARA (UiTM)Johor, Malaysia. International Journal of Management. Accounting and Economics, 2(3), 167-178.

Oyediran, W. O., Omoare, A. M., Owoyemi, M. A., Adejobi, A. O., \& Fasasi, R. B. (2020). Prospects and limitations of e-learning application in private tertiary institutions amidst COVID-19 lockdown in Nigeria. Heliyon, 6(11), e05457. Advance online publication. doi:10.1016/j.heliyon.2020.e05457 PMID:33241143

Oyedotun, T. D. (2020). Sudden change of pedagogy in education driven by COVID-19: Perspectives and evaluation from a developing country. Research in Globalization, 2, 100029. doi:10.1016/j.resglo.2020.100029

Packham, G., \& Miller, C. (2000). Peer-Assisted Student Support: A new approach to learning. Journal of Further and Higher Education, 24(1), 55-65. doi:10.1080/030987700112318 
Pugatch, T., \& Wilson, N. (2018). Nudging study habits: A field experiment on peer tutoring in higher education. Economics of Education Review, 62(November), 151-161. 10.1016/j.econedurev.2017.11.003

Salanova, M., Schaufeli, W., Martínez, I., \& Bresó, E. (2010). How obstacles and facilitators predict academic performance: The mediating role of study burnout and engagement. Anxiety, Stress, and Coping, 23(1), 53-70. doi:10.1080/10615800802609965 PMID:19326271

Sarker, S., Ahuja, M., Sarker, S., \& Kirkeby, S. (2011). The Role of Communication and Trust in Global Virtual Teams: A Social Network Perspective. Journal of Management Information Systems, 28(1), $273-309$. doi:10.2753/MIS0742-1222280109

Schuetz, E., Obirei, B., Salat, D., Scholz, J., Hann, D., \& Dethleffsen, K. (2017). A large-scale peer teaching programme - acceptance and benefit. Z. Evid. Fortbild. Qual. Gesundh. Wesen, 125, 71-79. doi:10.1016/j. zefq.2017.05.026 PMID:28599822

Wong \& Law. (2002). The effects of leader and follower emotional intelligence on performance and attitude: An exploratory study. The Leadership Quarterly, 13, 243-27.

Yu, T., Lu, L., \& Liu, T. (2010). Exploring factors that influence knowledge sharing behavior via weblogs. Computers in Human Behavior, 26(1), 32-41. doi:10.1016/j.chb.2009.08.002

Ala Oluwafolakemi Grace is a graduate student in the College of Economics and Management, Harbin Engineering University. She received her Master's degree in Information Management in Babcock University. Her current research interest covers Management and Applied Psychology.

Hongtao Yang is a professor of Management at the HuaQiao University, Quanzhou, China. His research interest is in emerging forms of electronic marketing. 